\title{
Effect of orexin A on apoptosis in BGC-823 gastric cancer cells via OX1R through the AKT signaling pathway
}

\author{
JING WEN $^{1}$, YUYAN ZHAO ${ }^{1}$, YANG SHEN $^{1}$ and LEI GUO ${ }^{2}$ \\ Departments of ${ }^{1}$ Endocrinology and ${ }^{2}$ Orthopedic Surgery, First Affiliated Hospital, \\ China Medical University, Shenyang, Liaoning 110001, P.R. China
}

Received January 11, 2014; Accepted July 22, 2014

DOI: $10.3892 / \mathrm{mmr} .2015 .3190$

\begin{abstract}
Orexins are a class of peptides involved in the regulation of food intake, energy homeostasis, the sleep-wake cycle and gastrointestinal function. Recent studies have demonstrated that orexin A may influence apoptosis and proliferation in numerous types of cancer cells. However, the effect of orexin A on gastric cancer cells and its mechanisms of action remain elusive. In the present study, BGC- 823 gastric cancer cells were treated with orexin $\mathrm{A}\left(10^{-10}-10^{-6} \mathrm{M}\right)$ in vitro and the expression levels of orexin receptor 1 (OX1R) protein in cells was then determined. The proliferation, viability and apoptosis of BGC-823 cells were detected. In addition, BGC-823 cells were treated with AKT inhibitor PF-04691502 or OX1R-specific antagonist SB334867 in combination with orexin $\mathrm{A}$, in order to examine the activation of $\mathrm{AKT}$ and caspase-3. The results showed that orexin A $\left(10^{-10}-10^{-6} \mathrm{M}\right)$ stimulated the OX1R protein expression in BGC-823 cells, which improved the proliferation and viability of the cells as well as protected them from apoptosis. Phosphorylated AKT protein was significantly increased in BGC-823 cells following treatment with orexin A. Moreover, $10^{-8} \mathrm{M}$ orexin A reduced the proapoptotic activity of caspase-3 (by $\leq 30 \%$ ). The OX1R antagonist SB334867 $\left(10^{-6} \mathrm{M}\right)$ and AKT antagonist PF-04691502 $\left(10^{-6} \mathrm{M}\right)$, when used individually or in combination, abolished the effect of orexin A $\left(10^{-8} \mathrm{M}\right)$ on BGC-823 cells. In conclusion, the results of the present study demonstrated that orexin A inhibited gastric cancer cell apoptosis via OX1R through the AKT signaling pathway.
\end{abstract}

\section{Introduction}

Orexin A and B are neuropeptides derived from the proteolytic cleavage of a common 130-amino acid precursor

Correspondence to: Professor Yuyan Zhao, Department of Endocrinology, First Affiliated Hospital, China Medical University, 155 Nanjing North Street, Shenyang, Liaoning 110001, P.R. China E-mail: g572@sina.com

Key words: orexin A, orexin receptor 1, apoptosis, AKT signaling pathway, gastric cancer cells peptide prepro-orexin. In humans their amino acids are $46 \%$ identical (1). These peptides act via two closely associated G-protein coupled receptors, the orexin receptors 1 (OX1R) and 2 (OX2R) for orexins $(1,2)$. OX1R appears to be highly selective for orexin A, whereas OX2R binds orexin A and B with similar affinity (3). Orexins are involved in the regulation of numerous body functions, including food intake (4), the sleep-wake cycle (4), breathing (5), the reward system $(4,6)$ and drug addiction (6,7). Orexin-producing neurons are present in the dorsal and lateral hypothalamus, where they project to and excite numerous structures of the brain (8). It has been reported that orexins are not restricted to the hypothalamus, but may also be expressed in peripheral tissues, including adrenals, gastrointestinal tract and endocrine pancreas (9).

It has been reported that orexins may also have a role in the proliferation of certain types of cancer cells (10). For example, orexins induced apoptosis in human colon cancer cell lines, which greatly reduced cell growth. This effect was observed in human neuroblastoma cells (10) and rat pancreatic tumor cells (11). However, orexin A stimulated cell proliferation in adrenal gland tumor cells, the effects of which were more remarkable in cultured adenomatous cells than in normal adrenocortical cells (12). In addition, orexin A had no effect on proliferation of rat C6 glioma cells (13). These studies added a novel dimension to the biological functions of orexins. However, to the best of our knowledge, the effects of orexin A on proliferation and apoptosis have not been demonstrated in gastric cancer cells.

Numerous studies have demonstrated that disorders of the phosphatidylinositol 3-kinase (PI3K)/AKT/mechanistic target of rapamycin (mTOR) signaling pathway are associated with the process of proliferation and apoptosis in various tumor cells (14-18). Phosphorylation of AKT occurs primarily in gastric cancer cells and activation of these cells can prolong their survival and increase proliferation, thereby promoting tumor development and angiogenesis (19). Moreover, phosphorylated AKT exerts anti-apoptotic effects through the phosphorylation of B-cell lymphoma-associated death promoter (Bad) (20) and caspase-9 (21). Therefore, AKT may be involved in the regulation of gastric cancer cell survival and apoptosis.

In the present study, BGC-823 gastric cancer cell apoptosis and proliferation assays were performed to evaluate the effect of orexin A on gastric cancer cell growth. Furthermore, 
cell death levels and caspase-3 activation were examined in order to determine the protective effect of orexin A against apoptosis. In addition, in order to verify the involvement of the PKB/AKT pathway, the activation of phosphorylated AKT and total AKT were examined following the treatment of cells with a series of concentrations of exogenous orexin $\mathrm{A}$ and associated inhibitors. The results of the present study provided evidence for the functional role of orexin A in gastric cancer cells via OX1R-stimulated AKT signaling pathway.

\section{Materials and methods}

Reagents. The orexin A and caspase-3 assay kits were obtained from Sigma (St. Louis, MO, USA). RPMI 1640 medium and fetal bovine serum (FBS) were purchased from Gibco-BRL (Grand Island, NY, USA). The AKT inhibitor PF-04691502 was purchased from Selleck (Houston, TX, USA). OX1R-specific antagonist SB334867 was obtained from Tocris (Minneapolis, MA, USA). The Cell Death Detection ELISA kit and Cell Proliferation ELISA bromodeoxyuridine (BrdU) colorimetric kit were purchased from Roche Diagnostics (Penzberg, Germany). Total/phospho-AKT (s473) polyclonal antibodies, $\beta$-actin (c4): sc-47778 mouse monoclonal antibody was purchased from Santa Cruz Biotechnology, Inc. (Santa Cruz, CA, USA). Total/phospho-AKT (s473) rabbit polyclonal antibodies and the OX1R rabbit polyclonal antibody were obtained from Abcam (Cambridge, UK).

Cell culture. Human BGC-823 gastric cancer cells were obtained from the American Type Culture Collection (Manassas, VA, USA) and maintained in RPMI 1640 medium supplemented with $10 \%$ (wt/vol) FBS, L-glutamine (2 mM), penicillin $(50 \mu \mathrm{g} / \mathrm{ml})$ and streptomycin $(100 \mu \mathrm{g} / \mathrm{ml})$ (Xianfeng, Shanghai, China). The cells were grown in a humidified atmosphere containing $5 \% \mathrm{CO}_{2}$ at $37^{\circ} \mathrm{C}$. Prior to an experiment, cells were grown in petri dishes in serum-free medium for $24 \mathrm{~h}$. The next day, cells were treated with different concentrations of orex in $\mathrm{A}\left(0,10^{-10}, 10^{-8}\right.$ and $\left.10^{-6} \mathrm{M}\right)$, or $10^{-8} \mathrm{M}$ orexin $\mathrm{A}$ with either SB334867, PF-04691502 or their combination for $20 \mathrm{~min}$.

Cell proliferation assays. BGC-823 gastric cancer cells were seeded $\left(2 \times 10^{3}\right.$ cells/well $)$ in 96 -well plates and cultured for $24 \mathrm{~h}$. To synchronize cell cycles, cells were serum-deprived for $24 \mathrm{~h}$ and then treated with various concentrations $\left(0,10^{-10}, 10^{-8}\right.$ and $\left.10^{-6} \mathrm{M}\right)$ of orexin $\mathrm{A}$ or $10^{-8} \mathrm{M}$ orexin $\mathrm{A}$ along with $10^{-6} \mathrm{M}$ OX1R antagonist SB334867 for a further $24 \mathrm{~h}$. BrdU solution $\left(10^{-6} \mathrm{M}\right)$ was then added and cells were incubated for $2.5 \mathrm{~h}$. BrdU incorporation into DNA was measured using the Cell Proliferation ELISA BrdU colorimetric kit (Roche Diagnostics).

Cell viability. BGC-823 gastric cancer cells were seeded $\left(2 \times 10^{3}\right.$ cells/well) in 96 -well plates and cultured for $24 \mathrm{~h}$. Following incubation in a serum free RPMI 1640 medium supplemented with test agents for $48 \mathrm{~h}$, MTT (Sigma) solution $(0.5 \mathrm{mg} / \mathrm{ml})$ was added. After $3 \mathrm{~h}$, the culture medium was removed and the formazan crystals that formed were dissolved in $100 \mu \mathrm{l}$ dimethyl sulfoxide (Merck KGaA, Darmstadt, Germany). Optical density was measured using a plate reader (SpectraMax Plus384 microplate reader; Molecular
Devices, Ismaning, Germany) at 570 and $650 \mathrm{~nm}$ (reference wave/length).

Annexin V/propidium iodide (PI) assays for apoptosis. Apoptotic cells were quantified using the Annexin V/PI Apoptosis Detection kit and evaluated for apoptosis by BD Accuri $^{\text {TM }}$ C6 Flow Cytometer according to the manufacturer's instructions (BD Pharmingen, San Diego, CA, USA). Cells were treated with different concentrations of orexin $\mathrm{A}$ in the absence of serum for $48 \mathrm{~h}$. $1 \times 10^{5}$ cells were briefly washed twice with phosphate-buffered saline, then stained with $5 \mu \mathrm{l}$ Annexin V-fluorescein isothiocyanate (FITC) and $10 \mu \mathrm{l} \mathrm{PI}$ in $500 \mu \mathrm{l}$ binding buffer for $15 \mathrm{~min}$ at room temperature in the dark. Apoptosis was determined by counting the number of cells stained by FITC-labeled Annexin V by fluorescence-activated cell sorting analysis. Early apoptotic cells were identified as PI-negative and FITC-Annexin V positive; cells that were in late apoptosis or already dead were positive for PI as well as FITC-Annexin V.

Activity of caspase-3 in BGC-823 cells. BGC-823 cells were cultured in serum-free medium using six-well plates $\left(1.5 \times 10^{5}\right.$ cells/well). Culture medium was then replaced with fresh culture medium with or without orexins. After $24 \mathrm{~h}$, caspase-3 activity was assessed using a Caspase-3 Colorimetric Assay kit following the manufacturer's instructions (Sigma).

Polymerase chain reaction $(P C R)$. Total RNA was extracted from BGC-823 cells using TRIzol reagent (Invitrogen, Carlsbad, CA, USA). The expression of OX1R and OX2R messenger RNA (mRNA) was detected using PCR and TaqMan reagents (Takara, Otsu, Japan). The following specific primers were used: OX1R forward, 5'-TGC GGC CAA CCC TAT CAT CTA-3' and reverse, 5'-ACC GGC TCT GCA AGG ACA A-3'); OX2Rforward, 5'-ATC GCA GGG TAT ATC ATC GTG TTC-3' and reverse, 5'-TGA CTG TCC TCA TGT GGT GGT TC-3'. As an internal control for reverse transcription (RT) and reaction efficiency, amplification of GAPDH mRNA was performed in parallel for each sample. The following specific primers were used: GAPDH forward, 5'-GGC ACA GTC AAG GCT GAG AAT G-3' and reverse, 5'-ATG GTG GTG AAG ACG CCA GTA-3'. The PCR reactions were performed using the following conditions: $95^{\circ} \mathrm{C}$ for $30 \mathrm{sec}$, then 40 cycles of $95^{\circ} \mathrm{C}$ for $5 \mathrm{sec}, 60^{\circ} \mathrm{C}$ for $30 \mathrm{sec}$ and $95^{\circ} \mathrm{C}$ for $15 \mathrm{sec}$. All primers and TaqMan probes specific to OX1R, OX2R and GAPDH were designed using Primer Premier 5.0 software (Premier Biosoft International, Palo Alto, CA, USA).

Protein preparations and western blot analysis. BGC-823 cells were washed with cold PBS and harvested in radioimmunoprecipitation assay buffer (Beyotime Biotechnology, Jiangsu, China) containing protease inhibitors like phenylmethylsulfonyl fluoride (Beijing, Jiangsu, China) and phosphatase inhibitors (KeyGEN Biotech Co., Ltd., Nanjing, China). Cell lysates were incubated on ice for $30 \mathrm{~min}$, then collected and centrifuged at $12,000 \mathrm{x} \mathrm{g}$ for $10 \mathrm{~min}$ at $4^{\circ} \mathrm{C}$. The supernatants were collected, mixed with $5 \mathrm{X}$ loading buffer and then denatured by boiling for $10 \mathrm{~min}$. Samples were separated by SDS-PAGE and transferred to polyvinylidene fluoride membranes at $60 \mathrm{~V}$ for $2.5 \mathrm{~h}$ in a transfer buffer containing $20 \mathrm{mM}$ Tris (bioWORLD, 
A

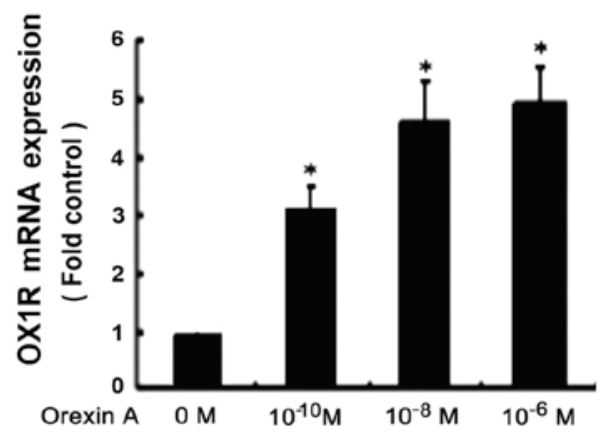

B
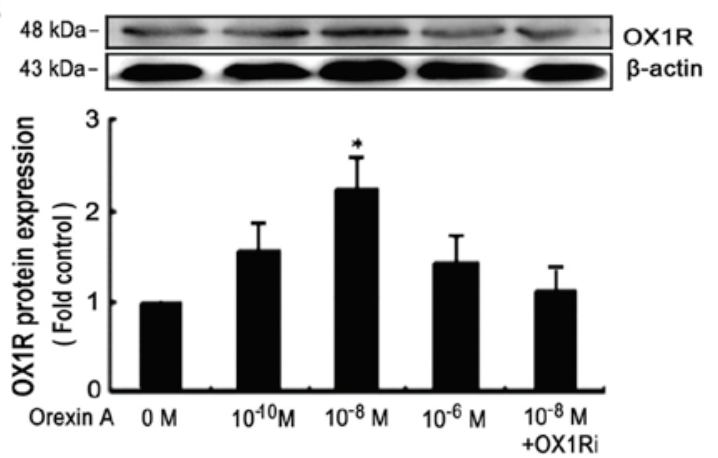

Figure 1. Effect of orexin A on OX1R mRNA and protein expression in BGC-823 cells. Cells were exposed to orexin A at concentrations of $0,10^{-10}$, $10^{-8}$ and $10^{-6} \mathrm{M}$ for $24 \mathrm{~h}$. Another group was treated with $10^{-6} \mathrm{M}$ orexin $\mathrm{A}$ in the presence of OX1Ri $\left(10^{-6} \mathrm{M}\right)$. The expression of (A) OX1R mRNA and (B) OX1R protein was measured via polymerase chain reaction and western blot analysis. Data are presented as the mean \pm standard error of the mean based on triplicate determinations from a representative experiment. ${ }^{*} \mathrm{P}<0.05$ vs. control. OX1R, orexin receptor 1; OX1Ri, OX1R antagonist SB334867; mRNA, messenger RNA.

Dublin, OH, USA), 150 mM glycine (Solarbio, Beijing, China) and $20 \%$ methanol (Xinxing, Liaoning, China). Membranes were then incubated with a primary antibody against OX1R at a 1:250 dilution or phospho/total-AKT at a 1:1,000 dilution in TBST overnight at $4^{\circ} \mathrm{C}$. The membranes were washed and incubated with horseradish peroxidase-conjugated anti-species secondary antibody for $1.5 \mathrm{~h}$ at room temperature, and then washed three times with TBST for $30 \mathrm{~min}$. Protein were visualized by BeyoECL (Beyotime Biotechnology, Jiangsu, China). Band densities were measured using Quantity-One V4.6.2 software (Bio-Rad, Hercules, CA, USA).

Statistical analysis. Values are expressed as the mean \pm standard error of the mean and differences between the means were analyzed by one-way analysis of variance. $\mathrm{P}<0.05$ was considered to indicate a statistically significant difference between values. Statistical analysis was performed using the SPSS 15.0 software package (SPSS Inc., Chicago, IL, USA).

\section{Results}

Orexin A stimulates OX1R protein expression in BGC-823 cells. BGC-823 cells were cultured for $24 \mathrm{~h}$ at $37^{\circ} \mathrm{C}$ and treated with orexin A at concentrations of $0,10^{-10}, 10^{-8}$ and $10^{-6} \mathrm{M}$, for $24 \mathrm{~h}$. PCR assays demonstrated that OX1R mRNA was expressed in BGC-823 cells (Fig. 1A). However, OX2R mRNA was not detected under identical conditions (data not shown). Treatment

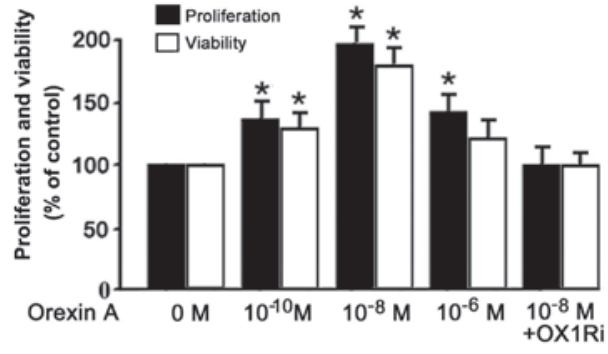

Figure 2. Proliferation and viability of BGC-823 cells following incubation with orexin A. Cells were treated with orexin A at concentrations of $0,10^{-10}$, $10^{-8}$ and $10^{-6} \mathrm{M}$ for $24 \mathrm{~h}$. In addition, a separate group of cells was treated with $10^{-8} \mathrm{M}$ orexin A in the presence of OX1Ri $\left(10^{-6} \mathrm{M}\right)$ for $24 \mathrm{~h}$. Proliferation and viability were determined using the BrdU assay and MTT test. Data are presented as the mean \pm standard error of the mean based on triplicate determinations from a representative experiment. ${ }^{*} \mathrm{P}<0.05$ vs. control. OX1Ri, orexin receptor 1 antagonist SB334867; BrdU, bromodeoxyuridine.

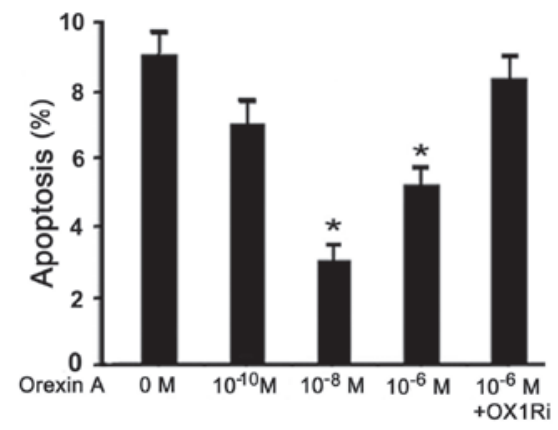

Figure 3. Orexin A protects BGC-823 cells from apoptosis. Cells were exposed to orexin A at concentrations of $0,10^{-10}, 10^{-8}$ and $10^{-6} \mathrm{M}$ for $24 \mathrm{~h}$, or cells treated with $10^{-6} \mathrm{M}$ orexin $\mathrm{A}$ in the presence of OX1Ri $\left(10^{-6} \mathrm{M}\right)$. Apoptosis was assessed using the Cell Death Detection ELISA kit. Data are presented as the mean \pm standard error of the mean based on triplicate determinations from a representative experiment. ${ }^{*} \mathrm{P}<0.05$ vs. control. OX1Ri, orexin receptor 1 antagonist SB334867.

with Orexin A caused a dose-dependent increase of OX1R protein expression in BGC-823 cells with $10^{-6} \mathrm{M}$ being the most potent concentration of orexin A ( 2.1-fold increase) (Fig. 1B). Orexin A $\left(10^{-8} \mathrm{M}\right)$ in the presence of $10^{-6} \mathrm{M} \mathrm{SB334867,}$ a high-affinity OX1R-specific non-peptide antagonist, significantly inhibited the expression of OX1R protein (Fig. 1B).

Effects of orexin $A$ on proliferation and viability of $B G C-823$ cells. To determine the effects of orexin $\mathrm{A}$ on cell survival, BGC-823 cells were stimulated with orexin A at concentrations $\left(0,10^{-6}, 10^{-8}\right.$ and $\left.10^{-10} \mathrm{M}\right)$ in combination with OX1R antagonist SB334867 $\left(10^{-6} \mathrm{M}\right)$. The cells were serum-starved for $24 \mathrm{~h}$ prior to exposure to the tested compounds in order to avoid interactions with growth factors and other mediators present in serum. An MTT assay showed that orexin A, at all the tested concentrations, significantly promoted the proliferation and viability of XR0416R cells $(\mathrm{P}<0.05$; Fig. 2). The present study determined that treatment with $10^{-8} \mathrm{M}$ orexin $\mathrm{A}$ increased cell proliferation and viability by 1.5 -fold compared with that of the control. The proliferation and viability of the group of cells treated with orexin $\mathrm{A}\left(10^{-8} \mathrm{M}\right)$ and OX1R-specific antagonist SB334867 were not significantly higher than those of the control. This therefore indicated that 


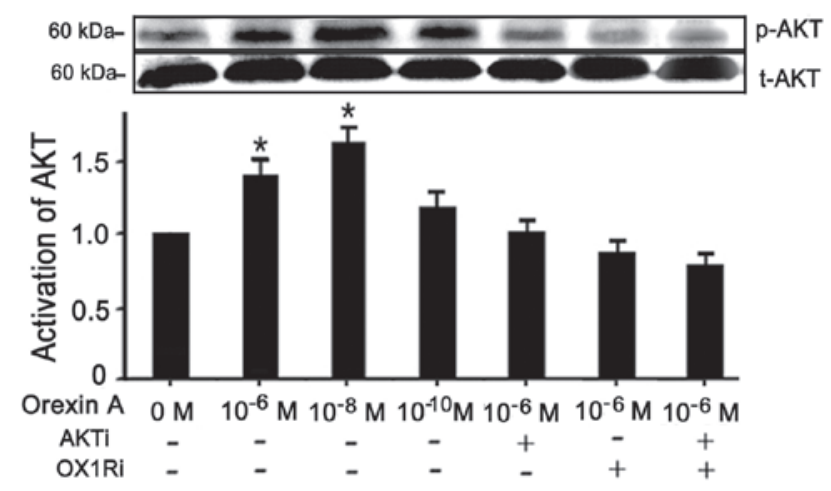

Figure 4. Orexin A increases BGC-823 cell proliferation via AKT signaling pathway. BGC-823 cells were treated with orexin A $\left(0,10^{-10}, 10^{-8}\right.$ and $\left.10^{-6} \mathrm{M}\right)$ for $20 \mathrm{~min}$ in the presence or absence of AKTi $\left(10^{-6} \mathrm{M}\right)$, OX1Ri $\left(10^{-6} \mathrm{M}\right)$ or a combination of both. The protein activation of p-AKT (corresponds to $60 \mathrm{kDa}$ ) was normalized against the total protein activation. $\beta$-actin protein expression was used as an internal control for equal protein loading. Protein activation was measured by western blot analysis. Data are presented as the mean \pm standard error of the mean based on triplicate determinations from a representative experiment. "P<0.05 vs. control. AKTi, AKT inhibitor PF-04691502; OX1Ri, orexin receptor 1 antagonist SB334867; p/t-AKT, phosphorylated/total AKT.

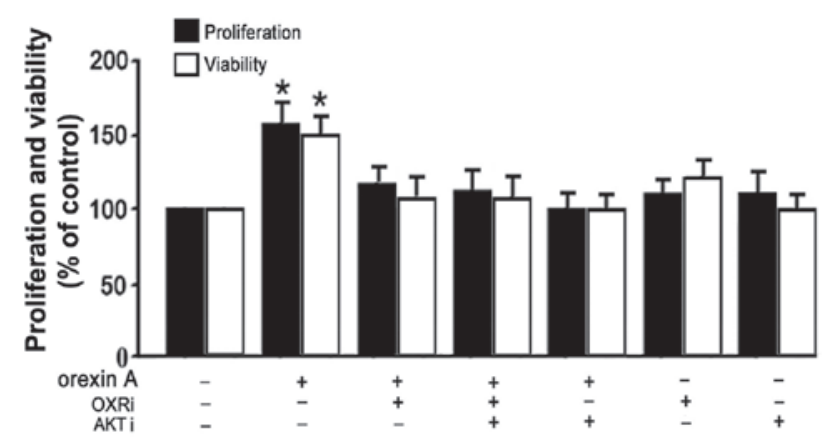

Figure 5. Effect of orexin A on the proliferation and viability of BGC-823 cells via stimulation of the AKT signaling pathway. Cells were exposed to orexin A at concentrations of 0 and $10^{-8} \mathrm{M}$ for $24 \mathrm{~h}$ in the presence or absence of AKTi, OX1Ri or a combination of both. In addition, cells were incubated with AKTi and OX1Ri without orexin A treatment for $24 \mathrm{~h}$. Proliferation and viability were determined using the BrdU assay and MTT test. Data are presented as the mean \pm standard error of the mean based on triplicate determinations from a representative experiment. ${ }^{*} \mathrm{P}<0.05$ vs. control. AKTi, AKT inhibitor PF-04691502; OX1Ri, orexin receptor 1 antagonist SB334867; BrdU, bromodeoxyuridine.

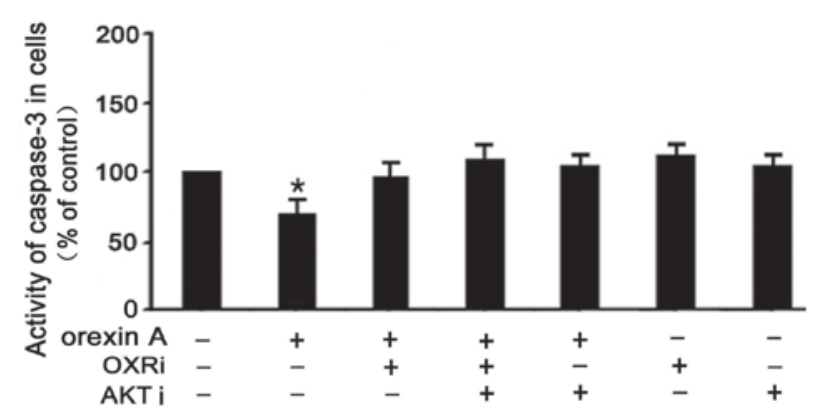

Figure 6. Effects of orexin A on caspase-3 activity in BGC-823 cells. Cells were treated with or without orexin $\mathrm{A}\left(10^{-8} \mathrm{M}\right)$ for $24 \mathrm{~h}$ in the presence or absence of AKTi, OX1Ri or a combination of both. Caspase-3 activity was assessed using a Caspase-3 Colorimetric Assay kit. Data are presented as the mean \pm standard error of the mean based on triplicate determinations from a representative experiment. ${ }^{*} \mathrm{P}<0.05$ vs. control. AKTi, AKT inhibitor PF-04691502; OX1Ri, orexin receptor 1 antagonist SB334867.
SB334867 significantly inhibited the proliferation and viability of BGC-823 cells in comparison with the cells exposed to orexin $\mathrm{A}\left(10^{-8} \mathrm{M}\right)$ at an identical concentration (Fig. 2).

Orexin A protects BGC-823 cells from apoptosis. Orexin A treatment $\left(10^{-10}, 10^{-8}\right.$ and $\left.10^{-6} \mathrm{M}\right)$ resulted in a decreased apoptotic index, measured using the Cell Death Detection ELISA kit. Concentrations of $10^{-8}$ and $10^{-6} \mathrm{M}$ orexin A resulted in a significant decrease in the apoptotic rate of H295R cells compared to that of the control $(\mathrm{P}<0.05)$ (Fig. 3); however, orexin $\mathrm{A}\left(10^{-6} \mathrm{M}\right)$ failed to protect cells against apoptosis in the presence of $10^{-6} \mathrm{M} \mathrm{SB} 334867$ (Fig. 3).

Orexin A enhances proliferation of BGC-823 cells via OXIR-evoked AKT signaling pathway. It is known that the $\mathrm{PI} 3 \mathrm{~K} / \mathrm{AKT}$ signaling pathway is involved in cell survival and apoptotic signaling; therefore, the present studies investigated whether orexin A-stimulation of BGC-823 cells induced activation of AKT $(22,23)$. The data confirmed a 1.5-fold increase of p-AKT protein in BGC-823 cells treated with $10^{-8} \mathrm{M}$ orexin A, compared to that of the untreated control cells $(\mathrm{P}<0.05)$ (Fig. 4). However, the total AKT levels remained unaffected by the aforementioned treatment. Moreover, $10^{-6} \mathrm{M}$ AKT antagonist PF-04691502 and $10^{-6}$ M OX1R antagonist SB334867 abolished the relative increase in AKT activation in response to orexin A, independently and in combination (Fig. 4).

Effects of orexin $A$ on proliferation and viability of $B G C-823$ cells through the AKT signaling pathway. In order to confirm the involvement of the AKT signaling pathway in orexin A-mediated proliferation and viability in BGC-823 cells, cell survival rates were determined using BrdU and MTT analysis. $10^{-8} \mathrm{M}$ orexin A significantly promoted the proliferation and viability of BGC-823 cells $(\mathrm{P}<0.05)$ (Fig. 5). However, these effects were blocked with AKT antagonist (PF-04691502), OX1R antagonist (SB334867) or their combination (Fig. 5). Moreover, the proliferation and viability were not changed significantly when treated with AKT antagonist or OX1R antagonist in the absence of orexin A co-treatment (Fig. 5). The data suggested that AKT participated in orexin A-induced stimulation of proliferation and viability of BGC-823 cells.

Effects of orexin A on caspase-3 activation in BGC-823 cells. To determine whether the activation of the caspase pathway was affected by orexin A, leading to the protection of BGC-823 cells from apoptosis, caspase-3 activity was measured. Treatment of BGC-823 cells with $10^{-8} \mathrm{M}$ orexin A significantly decreased caspase-3 activity (30\% below that of the control) (Fig. 6). This effect was reversed in the presence of PF-04691502 $\left(10^{-6} \mathrm{M}\right)$, SB334867 $\left(10^{-6} \mathrm{M}\right)$ and a combination of the inhibitors (Fig. 6). These results indicated that apoptosis induced by orexin A was mediated, at least in part, through caspase-3.

\section{Discussion}

The present study demonstrated, for the first time, to the best of our knowledege, that OX1R was expressed at mRNA and protein levels in BGC-823 gastric cancer cells. In order to explore the potential role of orexins in BGC-823 gastric 
cancer cells, the effects of orexin A on BGC-823 cell proliferation and apoptosis were examined. Orexin A stimulated the proliferation and viability of BGC-823 gastric cancer cells and protected them from apoptosis via the AKT signaling pathway.

Evidence suggested that the effects of orexin A on proliferation and apoptosis may vary dependent on the type of cancer cells (10-13). For example, orexin A suppressed cell growth by inducing apoptosis in human colon cancer, neuroblastoma cells and rat pancreatic tumor cells $(10,11)$. However, orexin A has also been reported to stimulate cell proliferation in adrenal gland tumor cells; the effects were more marked in cultured adenomatous than those in normal adrenocortical cells (12). In addition, orexin A had no effect on proliferation of rat C6 glioma cells, as assessed using a $\left({ }^{3} \mathrm{H}\right)$ thymidine incorporation assay (13). PI3K/PKB activators stimulated cell proliferation and viability in 3T3-L1 cells $(24,25)$. However, a more recent study showed that PI3K/PKB was not essential for orexin A-induced stimulation of proliferation and viability in 3T3-L1 preadipocytes (26). The mechanisms by which orexin A has opposing effects on apoptosis in different cancer cell types remains to be elucidated. One possible explanation may be that cells have different intrinsic sensitivities to cytochrome $c$. The differential sensitivity to cytochrome $\mathrm{c}$ may be due to high levels of apoptotic protease activating factor 1 (Apaf-1) in tumor tissues, such as neuroblastoma, in comparison with low levels of Apaf-1 in the adjacent brain tissue (27). Cytochrome c, once released from the mitochondria, binds to Apaf-1, leading to the formation of the apoptosome and the recruitment of procaspase-9. Activated caspase- 9 activates caspase-3 and caspase-7, thereby promoting cell death (28). Another possible explanation of what determines the influence of orexins on cell apoptosis may be the activation of mitogen-activated protein kinase (MAPK) signaling pathways. Studies have reported the expression of stable OX1R in human embryonic kidney-293 and Chinese hamster ovary cells. These studies have shown that orexins can exert converse effects on cell apoptosis through activation of the classical MAPK signaling pathways $(29,30)$. The extracellular signal-regulated kinase $1 / 2$ pathway was shown to protect against apoptosis, whereas p38 was a key promoter of cell death $(29,30)$. In addition, it has also been reported that activation of OX1R resulted in mobilization of intracellular calcium through a Gq-dependent mechanism (31). Although increases of cytosolic calcium are well known to occur during cell apoptosis, this does not provide sufficient evidence to explain the proapoptotic effect of orexins (32). Numerous GPCRs in human colon cancer cells are known to promote intracellular $\mathrm{Ca}^{2+}$ mobilization (33-35). These receptors include NT1 receptors for neurotensin (33), protease-activated receptors 1 for thrombin (34), protease-activated receptors 2 for trypsin (35) or muscarinic M3 receptors for acetylcholine (36). These receptors do not trigger apoptosis but conversely stimulate cell proliferation.

In the present study, orexin $\mathrm{A}$, at all tested concentrations, significantly promoted the proliferation and viability of BGC-823 gastric cancer cells. In addition, the effects of orexin $\mathrm{A}$ on proliferation and apoptosis in BGC-823 gastric cancer cells were blocked by AKT-specific inhibitors. This suggested the involvement of the activated PI3K/AKT signaling pathway in gastric cell proliferation and apoptosis induced by orexin A. The PI3K pathway has an important role in cell growth, proliferation, survival and apoptosis. Abnormal cell signaling via this pathway occurs in diverse types of cancer $(37,38)$. PI3K is activated by both receptor tyrosine kinases and Ras, and in turn activates multiple downstream signaling pathways. The AKT family, a multifunctional serine-threonine protein kinase, is a major downstream signaling molecule of PI3K and a critical target of PI3K in human cancer. PI3K/AKT signaling has been shown to be activated in various types of cancer. Activated AKT phosphorylates Bad and caspase-9 and the activated nuclear factor kappa-light-chain-enhancer of activated B cells pathway may promote resistance to apoptosis in cancer cells (39-43). In the present study, it was demonstrated that BGC-823 gastric cancer cells treated with orexin A had lower rates of apoptosis than the control treated cells. Orexin A treatment caused a significant decrease in caspase- 3 activity in BGC-823 cells. Caspase-3 is a key molecule involved in the execution of apoptosis and acts downstream in the apoptotic cascade (44). Although not documented in the present study, other caspase pathways can be studied in the future. It is necessary to investigate whether caspases are involved in the extrinsic (receptor-mediated) pathway of apoptosis. Furthermore, by employing the AKT-specific inhibitor PF-04691502, the present study demonstrated that orexin A inhibited apoptosis and regulated apoptosis-associated proteins in BGC-823 gastric cancer cells via AKT signaling pathways. Overall, the results of the present study suggested that orexin A promoted the activation of the PI3K/AKT pathway to inhibit the apoptosis of gastric cancer cells. However, further studies are required to clarify the mechanism by which orexin A modulates activation of $\mathrm{PI} 3 \mathrm{~K} / \mathrm{AKT}$ and other crucial signaling pathways for cancer cell survival and chemoresistance.

In conclusion, the present study provided the first evidence for the presence of orexin receptors in BGC-823 gastric cancer cells. Furthermore, the study showed that orexin A regulated BGC-823 gastric cancer cell proliferation and survival, reduced pro-apoptotic caspase-3 activity, and protected against apoptotic death via OX1R through the AKT signaling pathway.

\section{Acknowledgements}

The authors would like to thank The China Medical University Affiliated Hospital Laboratory Center for kindly providing the equipment. This study was supported by the National Natural Science Foundation of China (grant nos. 30872724, 81071460 and 81271996) and the Natural Science Foundation of Liaoning Province (grant no. 201202292).

\section{References}

1. Sakurai T, Amemiya A, Ishii M, Matsuzaki I, Chemelli RM, Tanaka H, Williams SC, Richardson JA, Kozlowski GP, Wilson $\mathrm{S}$, et al: Orexins and orexin receptors: a family of hypothalamic neuropeptides and $\mathrm{G}$ protein-coupled receptors that regulate feeding behavior. Cell 92: 573-585, 1998.

2. Kukkonen JP, Holmqvist T, Ammoun S and Akerman KE: Functions of the orexinergic/hypocretinergic system. Am J Physiol Cell Physiol 283: C1567-C1591, 2002. 
3. de Lecea L, Kilduff TS, Peyron C, Gao X, Foye PE, Danielson PE, Fukuhara C, Battenberg EL, Gautvik VT, Bartlett FS II, et al: The hypocretins: hypothalamus-specific peptides with neuroexcitatory activity. Proc Natl Acad Sci USA 95: 322-327, 1998.

4. Matsuki T and Sakurai T: Orexins and orexin receptors: from molecules to integrative physiology. Results Probl Cell Differ 46: 27-55, 2008.

5. Gestreau C, Bévengut $M$ and Dutschmann M: The dual role of the orexin/hypocretin system in modulating wakefulness and respiratory drive. Curr Opin Pulm Med 14: 512-518, 2008.

6. Aston-Jones G, Smith RJ, Sartor GC, Moorman DE, Massi L, Tahsili-Fahadan P and Richardson KA: Lateral hypothalamic orexin/hypocretin neurons: a role in reward-seeking and addiction. Brain Res 1314: 74-90, 2010.

7. Kodadek T and Cai D: Chemistry and biology of orexin signaling. Mol Biosyst 6: 1366-1375, 2010.

8. Nambu T, Sakurai T, Mizukami K, Hosoya Y, Yanagisawa M and Goto K: Distribution of orexin neurons in the adult rat brain. Brain Res 827: 243-260, 1999.

9. Voisin T, Rouet-Benzineb P, Reuter N and Laburthe M: Orexins and their receptors: structural aspects and role in peripheral tissues. Cell Mol Life Sci 60: 72-87, 2003.

10. Rouet-Benzineb P, Rouyer-Fessard C, Jarry A, Avondo V, Pouzet C, Yanagisawa M, Laboisse C, Laburthe $\mathrm{M}$ and Voisin T: Orexins acting at native $\mathrm{OX}(1)$ receptor in colon cancer and neuroblastoma cells or at recombinant OX(1) receptor suppress cell growth by inducing apoptosis. J Biol Chem 279: 45875-45886, 2004.

11. Voisin T, Firar AE, Avondo V and Laburthe M: Orexin-induced apoptosis: the key role of the seven-transmembrane domain orexin type 2 receptor. Endocrinology 147: 4977-4984, 2006.

12. Spinazzi R, Rucinski M, Neri G, Malendowicz LK and Nussdorfer GG: Prepro Orexin and orexin receptors are expressed in cortisol-secreting adrenocortical adenomas, and orexins stimulate in vitro cortisol secretion and growth of tumor cells. J Clin Endocrinol Metab 90: 3544-3549, 2005.

13. Biegańska K, Sokołowska P, Jöhren O and Zawilska JB Orexin A suppresses the growth of rat C6 glioma cells via a caspase-dependent mechanism. J Mol Neurosci 48: 706-712, 2012.

14. Martin JL and Baxter RC: Expression of insulin-like growth factor binding protein-2 by MCF-7 breast cancer cells is regulated through the phosphatidylinositol 3-kinase/AKT/mammalian target of rapamycin pathway. Endocrinology 148: 2532-2541, 2007.

15. Chow S, Minden MD and Hedley DW: Constitutive phosphorylation of the S6 ribosomal protein via mTOR and ERK signaling in the peripheral blasts of acute leukemia patients. Exp Hematol 34: 1183-1191, 2006.

16. Bessard A, Frémin C, Ezan F, Coutant A and Baffet G: MEK/ERK-dependent uPAR expression is required for motility via phosphorylation of P70S6K in human hepatocarcinoma cells. J Cell Physiol 212: 526-536, 2007.

17. Papadimitrakopoulou V and Adjei AA: The Akt/mTOR and mitogen-activated protein kinase pathways in lung cancer therapy. J Thorac Oncol 1: 749-751, 2006.

18. Chan SM, Weng AP, Tibshirani R, Aster JC and Utz PJ: Notch signals positively regulate activity of the mTOR pathway in T-cell acute lymphoblastic leukemia. Blood 110: 278-286, 2007.

19. Han Z, Wu K, Shen H, Li C, Han S, Hong L, Shi Y, Liu N, Guo C, Xue Y, et al: Akt1/protein kinase B alpha is involved in gastric cancer progression and cell proliferation. Dig Dis Sci 53: 1801-1810, 2008.

20. Downward J: Mechanisms and consequences of activation of protein kinase B/Akt. Curr Opin Cell Biol 10: 262-267, 1998.

21. Kim JH, Go HY, Jin DH, Kim HP, Hong MH, Chung WY, Park JH, Jang JB, Jung H, Shin YC, et al: Inhibition of the PI3K-Akt/PKB survival pathway enhanced an ethanol extract of Rhus verniciflua Stokes-induced apoptosis via a mitochondrial pathway in AGS gastric cancer cell lines. Cancer Lett 265: 197-205, 2008.

22. Liu M, Li CM, Chen ZF, Ji R, Guo QH, Li Q, Zhang HL and Zhou YN: Celecoxib regulates apoptosis and autophagy via the PI3K/Akt signaling pathway in SGC-7901 gastric cancer cells. Int J Mol Med 33: 1451-14588, 2014.

23. Walczak K, Turski WA and Rajtar G: Kynurenic acid inhibits colon cancer proliferation in vitro: effects on signaling pathways. Amino Acids 46: 2393-2401, 2014.

24. Kim MS, Yoon CY, Jang PG, Park YJ, Shin CS, Park HS Ryu JW, Pak YK, Park JY, Lee KU et al: The mitogenic and antiapoptotic actions of ghrelin in 3T3-L1 adipocytes. Mol Endocrinol 18: 2291-2301, 2004.
25. Gagnon A, Dods P, Roustan-Delatour N, Chen CS and Sorisky A: Phosphatidylinositol-3,4,5-trisphosphate is required for insulin-like growth factor 1-mediated survival of 3T3-L1 preadipocytes. Endocrinology 142: 205-212, 2001.

26. Skrzypski M, Kaczmarek P, Le TT, Wojciechowicz T, Pruszyńska-Oszmalek E, Szczepankiewicz D, Sassek M, Arafat A, Wiedenmann B, Nowak KW and Strowski MZ: Effects of orexin A on proliferation, survival, apoptosis and differentiation of 3T3-L1 preadipocytes into mature adipocytes. FEBS Lett 586: 4157-4164, 2012.

27. Johnson CE, Huang YY, Parrish AB, Smith MI, Vaughn AE, Zhang Q, Wright KM, Van Dyke T, Wechsler-ReyaRJ,Kornbluth S and Deshmukh M: Differential Apaf-1 levels allow cytochrome $\mathrm{c}$ to induce apoptosis in brain tumors but not in normal neural tissues. Proc Natl Acad Sci USA 104: 20820-20825, 2007.

28. Danial NN and Korsmeyer SJ: Cell death: critical control points Cell 116: 205-219, 2004.

29. Ammoun S, Lindholm D, Woolz H, Akerman KE and Kukkonen JP: G-protein-coupled OX1 orexin/hcrtr-1 hypocretin receptors induce caspase-dependent and -independent cell death through p38-/stress-activated protein kinase. J Biol Chem 281: 834-842, 2006.

30. Tang J, Chen J, Ramanjaneya M, Punn A, Conner AC and Randeva HS: The signalling profile of recombinant human orexin-2 receptor. Cell Signal 20: 1651-1661, 2008.

31. Darker JG, Porter RA, Eggleston DS, Smart D, Brough SJ, Sabido-David C and Jerman JC: Structure-activity analysis of truncated orexin-A analogues at the orexin-1 receptor. Bioorg Med Chem Lett 11: 737-740, 2001.

32. Rizzuto R, Pinton P, Ferrari D, Chami M, Szabadkai G, Magalhães PJ, Di Virgilio F, and Pozzan T: Calcium and apoptosis: facts and hypotheses. Oncogene 22: 8619-8627, 2003.

33. Maoret JJ, Anini Y, Rouyer-Fessard C, Gully D and Laburthe M: Neurotensin and a non-peptide neurotensin receptor antagonist control human colon cancer cell growth in cell culture and in cells xenografted into nude mice. Int J Cancer 80: 448-454, 1999.

34. Darmoul D, Gratio V, Devaud H, Lehy T and Laburthe M: Aberrant expression and activation of the thrombin receptor protease-activated receptor-1 induces cell proliferation and motility in human colon cancer cells. Am J Pathol 162: 1503-1513, 2003.

35. DarmoulD,GratioV,DevaudHandLaburtheM:Protease-activated receptor 2 in colon cancer: trypsin-induced MAPK phosphorylation and cell proliferation are mediated by epidermal growth factor receptor transactivation. J Biol Chem 279: 20927-20934, 2004.

36. Keely SJ, Uribe JM and Barrett KE: Carbachol stimulates transactivation of epidermal growth factor receptor and mitogen-activated protein kinase in T84 cells. Implications for carbachol-stimulated chloride secretion. J Biol Chem 273: 27111-27117, 1998.

37. Cantley LC: The phosphoinositide 3-kinase pathway. Science 296: 1655-1657, 2002.

38. Shaw RJ and Cantley LC: Ras, PI(3)K and mTOR signalling controls tumour cell growth. Nature 441: 424-430, 2006.

39. Li Y, Liu J, Liu X, Xing K, Wang Y, Li F and Yao L: Resveratrol-induced cell inhibition of growth and apoptosis in MCF7 human breast cancer cells are associated with modulation of phosphorylated Akt and caspase-9. Appl Biochem Biotechnol 135: 181-192, 2006.

40. Zhang G, Li M, Zhu X, Bai Y and Yang C: Knockdown of akt sensitizes osteosarcoma cells to apoptosis induced by Cisplatin treatment. Int J Mol Sci 12: 2994-3005, 2011.

41. Song L, Xiong H, Li J, Liao W, Wang L, Wu J and Li M Sphingosine kinase-1 enhances resistance to apoptosis through activation of PI3K/Akt/NF-kappaB pathway in human non-small cell lung cancer. Clin Cancer Res 17: 1839-1849, 2011.

42. Zhu Z, Sun H, Ma G, Wang Z, Li E, Liu Y and Liu Y: Bufalin induces lung cancer cell apoptosis via the inhibition of pi3k/akt pathway. Int J Mol Sci 13: 2025-2035, 2012.

43. Liu Q, Dong HW, Sun WG, Liu M, Ibla JC, Liu LX, Parry JW, Han XH, Li MS and Liu JR: Apoptosis initiation of $\beta$-ionone in SGC-7901 gastric carcinoma cancer cells via a PI3K-AKT pathway. Arch Toxicol 87: 481-490, 2013.

44. Creagh EM, Conroy H and Martin SJ: Caspase-activation pathways in apoptosis and immunity. Immunol Rev 193: 10-21, 2003. 